\title{
PENGARUH KELAS SOSIAL TERHADAP PERILAKU KONSUMEN (Studi Pada Pembelian Rumah di PERUM PERUMNAS Cabang Mojokerto Lokasi Madiun)
}

\author{
Ria Dwi Nugraheni \\ Pendidikan Ekonomi FKIP UNIVERSITAS PGRI MADIUN \\ riadnugraheni@gmail.com
}

\begin{abstract}
This research aim to know social class at PERUMNAS Branch Mojokerto Madiun location, to know consumer behavior at PERUMNAS Branch Mojokerto Madiun location, and to know influence of social class to consumer behavior at PERUM PERUMNAS Branch of Mojokerto Madiun location. Determination of samples in this study using a saturated sampling technique that is as many as 56 consumers who have bought houses of various types in PERUMNAS Branch Mojokerto Location Madiun. Data collection techniques used questionnaires, observations, interviews, and documentation. The results showed that obtained the results of simple linear regression test is $Y=17.668+1.256 \mathrm{X}$, the constant of 17.668. The result of t test is got the value of rhitung equal to 15.163 and ttabel equal to 1.67252. If rhitung $\geq$ ttable, then the calculation in accordance with the test criteria $t$. The result shows that rhitung (15.163) $\geq$ ttable (1.67252), it can be concluded that Ha accepted dah Ho rejected that social class significantly influence consumer behavior (Study on Purchase of House in PERUM PERUMNAS Branch of Mojokerto Madiun Location).
\end{abstract}

Keywords: Social Class, Consumer Behavior

\begin{abstract}
Abstrak
Penelitian ini bertujuan untuk mengetahui kelas sosial pada PERUM PERUMNAS Cabang Mojokerto Lokasi Madiun, untuk mengetahui perilaku konsumen pada PERUM PERUMNAS Cabang Mojokerto Lokasi Madiun, dan untuk mengetahui pengaruh kelas sosial terhadap perilaku konsumen pada PERUM PERUMNAS Cabang Mojokerto Lokasi Madiun. Penentuan sampel dalam penelitian ini menggunakan teknik sampling jenuh yaitu sebanyak 56 konsumen yang telah membeli rumah berbagai tipe di PERUM PERUMNAS Cabang Mojokerto Lokasi Madiun. Teknik pengumpulan data menggunakan angket, observasi, wawancara, dan dokumentasi. Hasil penelitian menunjukkan bahwa diperoleh hasil uji regresi linier sederhana adalah $\mathrm{Y}=17,668+$ 1,256 X, konstanta sebesar 17,668. Hasil uji t diperoleh nilai $r_{\text {hitung }}$ sebesar 15.163 dan $\mathrm{t}_{\text {tabel }}$ sebesar 1.67252. Jika $\mathrm{r}_{\text {hitung }} \geq \mathrm{t}_{\text {tabel }}$, maka perhitungan sesuai dengan kriteria uji t. Hasil menunjukkan bahwa $r_{\text {hitung }}(15.163) \geq t_{\text {tabel }}$ (1.67252), dapat disimpulkah bahwa Ha diterima dah Ho ditolak yaitu kelas sosial berpengaruh signifikan terhadap perilaku konsumen (Studi Pada Pembelian Rumah di PERUM PERUMNAS Cabang Mojokerto Lokasi Madiun).
\end{abstract}

Kata Kunci: Kelas Sosial, Perilaku Konsumen 


\section{PENDAHULUAN}

Sejalan dengan globalisasi yang berkembang saat ini, menuntut kehidupan yang lebih layak, nyaman dan lebih baik dari sebelumnya. Pada akhirnya banyak strategi yang dilakukan, seperti lebih unggul dalam pekerjaan, menambah penghasilan, sukses dalam pendidikan, sampai pada impian memiliki rumah sendiri.

Keinginan manusia untuk memiliki rumah sendiri dari pada menyewa rumah merupakan alasan utama kebutuhan perumahan sangat penting bagi kelangsungan hidup manusia. Tetapi pada kenyataannya saat ini penduduk Indonesia masih banyak yang belum memiliki rumah sendiri. Mereka memilih untuk menyewa rumah maupun tinggal bersama saudara.

Melihat dari permasalahan tersebut, menggerakkan produsen untuk berinisiatif dalam pengembangan bisnis perumahan seperti penjualan agen property perumahan. Penjualan agen property perumahan sudah banyak di temui pada kota-kota besar seperti di Kota Madiun. Penetapan harga, lokasi dan kualitas rumah juga saling bersaing sekaligus menjadi tambahan pertimbangan konsumen dalam membeli rumah, ditambah lagi dengan tersedianya fasilitas KPR (Kredit Kepemilikan Rumah).

Dalam ilmu perilaku konsumen, pemasar harus mengetahui kebutuhan konsumen dan memahami perilakunya dalam melakukan keputusan pembelian sebagai modal untuk menentukan kebijakan dalam pengembangan produk dengan melihat kelas sosial konsumen. "Studi tentang perilaku konsumen akan menjadi dasar yang amat penting dalam manajemen pemasaran" (Setiadi, 2010). Selain berorientasi pada kebutuhan konsumen, manajemen pemasaran juga fokus kepada kepuasan konsumen. Apabila produk yang dihasilkan memberikan kepuasan kepada konsumen di waktu sebelum membeli, saat membeli dan setelah membeli maka akan terciptanya kepercayaan konsumen pada perusahaan atau pemasar.

"Kelas sosial adalah divisi atau kelompok yang relatif homogen dan tetap dalam suatu masyarakat, yang tersusun secara hierarkis dan anggota-anggotanya memiliki nilai, minat dan perilaku yang mirip" (Kotler, dkk, 2000). Kelas sosial dibutuhkan oleh pemasar untuk menganalisa perilaku konsumen dalam membeli produk berdasarkan keinginannya. Konsumen akan memilih produk berdasarkan kelas sosialnya. Semakin tinggi klasifikasi kelas sosial seseorang, semakin tinggi pula selera produk yang dipilihnya melihat dari kualitas produk yang lebih baik, kemasan, corak apalagi tidak memikirkan harga. Berbeda dengan konsumen yang memiliki klasifikasi kelas sosial menengah dan rendah. Konsumen seperti ini cenderung melihat harga daripada corak, kualitas maupun kemasannya.

Perusahaan Umum Pembangunan Perumahan Nasional (PERUM PERUMNAS) Cabang Mojokerto Lokasi Madiun merupakan badan usaha milik negara sekaligus bisnis negara yang mempunyai keseluruhan modal berasal dari negara. Dalam setiap pembangunan perumahan, perusahaan umum ini mengutamakan kebutuhan konsumen demi mencapai kepuasan konsumen.

\section{Perilaku Konsumen}

Perilaku konsumen adalah tindakan individu dan sekelompok orang dalam menentukan pilihannya untuk mendapatkan barang dan jasa yang dibutuhkan pada saat itu dan akan berubah pada sepanjang waktu. Bilamana konsumen sudah mendapatkan produk dan jasa yang telah dipilihnya diharapkan menjadi keputusan yang cermat 
untuk memenuhi kebutuhan sehari-hari dengan melihat afeksi, kognisi, perilaku dan lingkungan konsumen. Perilaku konsumen merupakan dorongan konsumen untuk membuat keputusan dalam membeli, menggunakan dan menghabiskan sejumlah produk dan jasa. Perilaku konsumen yang baik akan mampu menambah kuantitas penjualan yang sangat diharapkan pemasar dalam pengembangan produk dan jasanya sehingga akan meningkatkan pendapatan dari penjualan produk dan jasa tersebut.

Indikator variabel perilaku konsumen dalam penelitian ini menggunakan teori Abdullah dan Tantri (2012) antara lain :

1. Faktor Budaya

2. Faktor Sosial

3. Faktor Pribadi

4. Faktor Psikologis

Faktor-faktor yang Mempengaruhi Konsumen

Menurut Dharmmesta dan Handoko (2013), menjelaskan bahwa faktor-faktor lingkungan ekstern yang mempengaruhi perilaku konsumen, yaitu: (1) kebudayaan (culture) dan kebudayaan khusus (subculture); (2) kelas sosial (social class); (3) kelompok-kelompok sosial (social group) dan kelompok referensi (reference group); dan (4) keluarga (family). Sedangkan faktor-faktor lingkungan intern yang mempengaruhi perilaku konsumen yaitu: (1) motivasi; (2) pengamatan; (3) belajar; (4) kepribadian dan konsep diri; dan (5) sikap.

\section{Kelas Sosial}

Kelas sosial merupakan lapisan sosial yang dimiliki oleh individu maupun sekelompok orang yang bisa terlihat lebih tinggi atau lebih rendah dari konsumen lainnya. Biasanya kelas sosial terlihat pada pekerjaan, penghasilan, pendidikan, kehormatan, kekuasaan konsumen. Dengan mengetahui kelas sosial konsumen, pemasar dapat mengidentifikasi kebutuhan konsumen serta perilaku sosialnya. Biasanya kelas sosial terlihat pada pekerjaan, penghasilan, pendidikan, kehormatan, kekuasaan konsumen. Dengan mengetahui kelas sosial konsumen, pemasar dapat mengidentifikasi kebutuhan konsumen serta perilaku sosialnya.

\section{Karakteristik Kelas Sosial}

Menurut Dharmmesta dan Handoko (2013), masyarakat kita, pada pokoknya dapat dikelompokkan ke dalam tiga golongan, yaitu :

1. Golongan Atas

Yang termasuk dalam kelas ini antara lain: pengusaha-pengusaha, pejabatpejabat tinggi.

2. Golongan Menengah

Yang termasuk dalam kelas ini antara lain: karyawan instansi, pemerintah, pengusaha menengah

3. Golongan Rendah

Yang termasuk dalam kelas ini: buruhburuh pabrik, pegawai rendah, tukang becak, dan pedagang kecil.

Indikator variabel kelas sosial dalam penelitian ini menggunakan teori Engel, dkk (1994), yang menjelaskan bahwa adalah penting untuk menyadari bahwa kelas sosial tidak langsung ditentukan oleh pendapatan. Hal yang menentukan kelas sosial, yaitu:

1. Pekerjaan

2. Prestasi Pribadi

3. Interaksi

4. Pemilikan

5. Orientasi Nilai

6. Kesadaran Kelas

\section{METODE PENELITIAN}

Desain penelitian yang digunakan dalam penelitian ini menggunakan sebab akibat (kausal). Menurut Sugiyono (2016), "hubungan kausal adalah hubungan yang bersifat sebab akibat. Jadi di sini ada 
variabel independen (variabel yang mempengaruhi) dan dependen (dipengaruhi)".

Metode penelitian yang digunakan dalam penelitian ini adalah metode deskriptif. Populasi dalam penelitian ini sebanyak 56 konsumen sekaligus sebagai sampel karena jumlah keseluruhan populasi kurang dari 100 sehingga keseluruhan dijadikan sampel. Teknik pengumpulan data menggunakan angket, observasi, dokumentasi dan wawancara. Angket digunakan untuk mengambil data kelas sosial dan perilaku konsumen dengan cara menyebar angket kepada konsumen dengan mengisi 9 pernyataan kelas sosial dan 16 pernyataan perilaku konsumen. Observasi dilakukan dengan mengamati secara langsung proses pembelian rumah di PERUM PERUMNAS Cabang Mojokerto Lokasi Madiun. Wawancara digunakan untuk mengetahui data kelas sosial dan perilaku konsumen dengan cara peneliti berbincang secara langsung dengan konsumen tentang kelas sosial maupun perilakunya saat membeli rumah di PERUM PERUMNAS Cabang Mojokerto Lokasi Madiun. Dokumentasi digunakan untuk mengambil data kelas sosial dan perilaku konsumen yang memperoleh informasi dari konsumen. Dengan demikian penelitian kuantitatif kausal - deskriptif dalam pemecahan masalahnnya, penelitian ini memperoleh informasi berdasarkan fakta yang ada.

Uji prasyarat atau instrumen menggunakan uji validitas menggunakan product moment. Uji reliabilitas menggunakan cronbach's al pha ( $\alpha$ ). Uji asumsi klasik menggunakan uji statistic One Sample Kolmogorov-Smirnov Test.

\section{Koefisien Determinasi (R-Square)}

Menurut Latan dan Temalagi (2013), "koefisien determinasi menunjukkan seberapa besar kemampuan variabel independen dalam menerangkan variasi variabel dependen".

\section{Uji Signifikansi t (Uji t)}

Menurut Latan dan Temalagi (2013), "Uji-t bertujuan untuk mengetahui secara individual pengaruh satu variabel independen terhadap variabel dependen".

\section{HASIL DAN PEMBAHASAN \\ Deskripsi Variabel Kelas Sosial}

Deskripsi variabel Kelas Sosial dengan jumlah responden sebanyak 56 konsumen, memiliki deskripsi data sebagai berikut : (1) Nilai rata-rata hitung (Mean) sebesar 37,91; (2) Median sebesar 39,00; (3) Modus sebesar 41; (4) Standar deviasi sebesar 5.279; (5) Nilai minimum sebesar 20; (6) Nilai maksimum sebesar 45; dan (6) Jumlah skor total sebesar 2123.

Hasil analisis deskriptif Kelas Sosial memiliki rata-rata sebesar 37,91 dan diperoleh hasil nilai di atas rata-rata sebanyak 38 konsumen atau 68\%, dan hasil nilai di bawah rata-rata sebanyak 18 konsumen atau $32 \%$. Dengan demikian, Kelas Sosial di PERUM PERUMNAS Cabang Mojokerto Lokasi Madiun cukup baik.

\section{Deskripsi Variabel Perilaku Konsumen}

Deskripsi variabel Perilaku Konsumen dengan jumlah responden sebanyak 56 konsumen, memiliki deskripsi data sebagai berikut : (1) Nilai rata-rata hitung (Mean) sebesar 65,41; (2) Median sebesar 67,00; (3) Modus sebesar 68; (4) Standar deviasi sebesar 7,387; (5) Nilai minimum sebesar 45; (6) Nilai maksimum sebesar 76; dan (6) Jumlah skor total sebesar 3663.

Hasil analisis deskriptif Perilaku Konsumen diperoleh hasil nilai di atas ratarata sebanyak 38 konsumen atau 53\%, sedangkan hasil nilai di bawah rata-rata sebanyak 18 konsumen atau 47\%. Artinya, Kelas Sosial di PERUM PERUMNAS 
Cabang Mojokerto Lokasi Madiun cukup baik.

\section{Hasil Uji Validitas}

Hasil uji validitas angket Kelas Sosial yang disebarkan kepada 56 konsumen pada PERUM PERUMNAS Cabang Mojokerto Lokasi Madiun berjumlah 9 pernyataan. Dari 9 pernyataan angket Kelas Sosial yang di uji dinyatakan valid dimana keseluruhan $r_{\text {hitung }} \geq r_{\text {tabel }}(0,2586)$.

Hasil uji validitas angket Perilaku Konsumen yang disebarkan kepada 56 konsumen pada PERUM PERUMNAS Cabang Mojokerto Lokasi Madiun berjumlah 16 pernyataan. Dari 16 pernyataan angket Perilaku Konsumen yang di uji dinyatakan valid dimana keseluruhan $r_{\text {hitung }}$ $\geq r_{\text {tabel }}(0,2586)$.

\section{Hasil Uji Reliabilitas}

Uji reliabilitas dikatakan reliabel apabila memperoleh nilai di atas 0,60. Hasil uji reliabilitas Kelas Sosial dan Perilaku Konsumen sebesar 0,837 dan 0,784 artinya keseluruhan variabel dinyatakan reliabel.

\section{Hasil Uji Asumsi Klasik}

Jika pada uji statistik OneKolmogorov Smirnov Test $\geq 0,05$ maka data berdistribusi normal. Dalam penelitian ini diperoleh hasil nilai Asymp. Sig sebesar 0,398 dimana lebih besar dari 0,05. Dengan demikian, data yang akan dianalisis terdistribusi normal.

\section{Hasil Uji Regresi Linier Sederhana}

Hasil uji regresi linier sederhana dalam penelitan ini diperoleh persamaan $\mathrm{Y}$ $=17,668+1,256 \mathrm{X}$. Konstanta sama dengan 17,668 , artinya jika variabel Kelas Sosial bernilai tetap atau konstant, maka besarnya Perilaku Konsumen adalah 17,668.

\section{Hasil Koefisien Determinasi (R-Square)}

Dari hasil koefisien determinasi (R-Square) dengan menggunakan program pengolahan data SPSS for Windows 16.0 diperoleh nilai sebesar 0,810 . Artinya, kelas sosial berpengaruh terhadap perilaku konsumen sebesar $81 \%$ sedangkan $19 \%$ diperngaruhi oleh variabel lainnya.

Hasil Uji T

Dari hasil uji $\mathrm{t}$ diperoleh hasil besar nilai $\mathrm{t}_{\text {hitung }} 15.163$, besar nilai $\mathrm{t}_{\text {tabel }} 1.67252$, besar nilai $\mathrm{Sig}_{\text {hit }} 0.000$, dan besar $\mathrm{Sig}_{\text {prob }}$ 0.05 . Artinya, nilai $t_{\text {hitung }}(15.163) \geq t_{\text {tabel }}$ $(1.67252)$ atau $\operatorname{Sig}_{\text {hit }}(0.000) \leq \operatorname{Sig}_{\text {prob }}$ (0.05). Dengan demikian, hipotesis penelitian ini menerima $\mathrm{H}_{\mathrm{a}}$ dan menolak $\mathrm{H}_{0}$. Penyataan hipotesis penelitian adalah Kelas Sosial berpengaruh signifikan terhadap Perilaku Konsumen pada PERUM PERUMNAS Cabang Mojokerto Lokasi Madiun.

\section{PENUTUP}

\section{Simpulan}

Berdasarkan teori pendukung, pembahasan dan hasil analisis data yang telah dijelaskan oleh peneliti pada bab sebelumnya, dapat di tarik simpulan sebagai berikut :

1. Kelas Sosial di PERUM PERUMNAS Cabang Mojokerto Lokasi Madiun cukup baik. Hal tersebut dapat diketahui pada hasil analisis data angket yang sebelumnya sudah disebarkan kepada 56 konsumen. yang berada di atas nilai ratarata sebanyak 38 konsumen atau sebesar $68 \%$ sedangkan yang berada di bawah nilai rata-rata sebanyak 18 konsumen atau sebesar $32 \%$.

2. Perilaku konsumen di PERUM PERUMNAS Cabang Mojokerto Lokasi Madiun cukup baik. Hal tersebut dapat diketahui pada hasil analisis data angket yang sebelumnya sudah disebarkan kepada 56 konsumen. yang berada di atas nilai ratarata sebanyak 30 konsumen atau sebesar 53\% sedangkan yang berada di bawah nilai rata-rata sebanyak 26 konsumen atau sebesar $18 \%$. 
3. Pengaruh Kelas Sosial Terhadap Perilaku Konsumen pada PERUM PERUMNAS Cabang Mojokerto Lokasi Madiun, terbukti dari hasil analisis uji regresi linier sederhana, uji determinasi (R-Square), dan uji signifikansi t (Uji t) mendapatkan hasil menerima $\mathrm{H}_{\mathrm{a}}$ dan menolak $\mathrm{H}_{0}$. Penyataan hipotesis penelitian ini adalah Kelas Sosial berpengaruh signifikan terhadap Perilaku Konsumen pada PERUM PERUMNAS Cabang Mojokerto Lokasi Madiun.

\section{Saran}

Berdasarkan kesimpulan yang diperoleh di dalam penelitian, maka peneliti mengajukan saran kepada PERUM PERUMNAS Cabang Mojokerto Lokasi Madiun dan peneliti selanjutnya sebagai berikut :

1. Bagi PERUM PERUMNAS Cabang Mojokerto Lokasi Madiun

PERUM PERUMNAS Cabang Mojokerto Lokasi Madiun, harus mampu mempertahankan pelayanan yang baik kepada konsumen dan selalu memberikan inovasi penjualan seperti promo harga maupun promosi produk perumahan agar menciptakan daya tarik konsumen untuk membeli rumah dan meningkatkan laba.
2. Bagi peneliti selanjutnya

Bagi peneliti yang akan datang sebaiknya mengembangkan penelitian ini dengan menambah variabel bebas lainnya, karena selain kelas sosial masih ada variabelvariabel lain yang dapat mempengaruhi perilaku konsumen di PERUM PERUMNAS Cabang Mojokerto Lokasi Madiun.

\section{DAFTAR PUSTAKA}

Engel James, dkk. (1994). Perilaku Konsumen Edisi Keenam Jilid 1. Jakarta. Binarupa Aksara.

Dharmmesta, Basu Swastha \& Hani Handoko. (2013). Manajemen Pemasaran Analisis Perilaku Konsumen. Yogyakarta. BPFE-Yogyakarta.

Kotler Philip, dkk. (2000). Manajemen Pemasaran Perspektif Asia. Yogyakarta. Penerbit Andi.

Swastha, Basu dan Irawan. (2005). Manajemen Pemasaran Modern. Yogyakarta. Liberty Yogyakarta.

\begin{tabular}{|c|c|c|}
\hline ـ- $\quad(201$ & 6). Metode & Penelitian \\
\hline Pendidikan & Pendekatan & Kuantitatif, \\
\hline $\begin{array}{l}\text { Kualitatif, } \\
\text { Penerbit Alf }\end{array}$ & $\begin{array}{c}\text { dan } \\
\text { abeta. }\end{array}$ & Bandung. \\
\hline
\end{tabular}

